\title{
Beyond Bradley and Behrendt: Building a stronger evidence-base about Indigenous pathways and transitions into higher education
}

\author{
Jack Frawley \\ Office of the Pro Vice Chancellor (Indigenous \\ Leadership), Charles Darwin University \\ jack.frawley@cdu.edu.au

\section{James A. Smith} \\ Office of the Pro Vice Chancellor (Indigenous \\ Leadership), Charles Darwin University \\ james.smith3@cdu.edu.au

\section{Steven Larkin} \\ Office of the Pro Vice Chancellor (Indigenous Leadership), Charles Darwin University \\ steven.larkin@cdu.edu.au
}

Successive Australian governments have addressed the issue of social inclusion and equity in higher education in a number of policies and reviews, the most recent being the Review of Australian Higher Education, the Bradley Review (Bradley et al. 2008); and the Review of Higher Education Access and Outcomes for Aboriginal and Torres Strait Islander People, the Behrendt Review (Behrendt et al. 2012).

The Bradley Review noted that although there had been success in areas of gender inequity in higher education, students from regional and remote areas, Indigenous students and those from low SES backgrounds were still seriously under-represented. The Bradley Review also found that the major barriers to the participation of students from low SES backgrounds were educational attainment, lower awareness of the long term benefits of higher education, less aspiration to participate, and the potential need for extra financial, academic or personal support once enrolled. As a result of the Bradley Review the Australian Government's policy Transforming Australia's Higher Education System announced two targets for the higher education sector: that by $2020,20 \%$ of undergraduate university students should be from low socio-economic backgrounds; and, that by $2025,40 \%$ of $25-34$ year olds should hold a bachelor degree. To support this policy, the Higher Education Participation and Partnerships Program (now rebadged Higher Education Participation Program) (HEPP) initiative came into being, with the participation component offering universities financial incentives to enroll and retain students from low SES backgrounds; and the partnerships component providing funding to raise student aspirations for higher education and working in partnership with other education institutions to do this (Gale \& Parker 2013).

We are continually learning more about the barriers to Indigenous higher education student participation in Australia, despite key challenges in relation to measurement and data collection (Wilks and Wilson 2015). We argue that a deeper understanding of Indigenous pathways and transitions into higher education is an important platform for better facilitating Indigenous participation and retention in higher education. The Behrendt Review called for initiatives to unlock the capacity of, and empower the choices of Indigenous students by building necessary skills and knowledge in order to "help individuals reach a point where they are eligible to enter higher education, should they so choose; and to inform their aspirations regarding higher education, particularly in relation to beliefs about who "belongs" at university and who doesn't" (Naylor, Baik \& James, 2013, p. 14). There were subsequent competitive grant rounds to invest in Indigenous focused HEPP projects in response to recommendations arising from the Behrendt 
Review. So what has happened in the field of Indigenous participation in higher education since then?

This special issue of Learning Communities highlights the types of initiatives that have been implemented across Australia in recent years that support increased Indigenous aspiration, access, participation and achievement in higher education. These include commentaries and evaluation reports based on existing programs (including those funded through HEPP) being delivered to support Indigenous pathways and transitions into higher education across Australia. We have contributions from Victoria, Queensland, Australian Capital Territory, News South Wales, Northern Territory and Western Australia.

Smith, Trinidad and Larkin use six Indigenous focused HEPP funded case studies to highlight consistent areas for action, including whole of community engagement approaches; the provision of adequate educational offerings and pathways; creating pathways to access higher education; clear transitional arrangements between VET, school and higher education; and access to online education and digital learning environments. Fricker presents a reflective account of leading the 'I Belong' program at RMIT. This has an explicit focus on the partnerships approach adopted to support its implementation, including those with the Ngarara Willim Centre for Aboriginal and Torres Strait Islander Peoples, Victorian Department of Education and a co-delivery model with the Australian Indigenous Mentoring Experience (AIME) program. The success of the AIME program is more comprehensively described in a paper by Priestly et al. This emphasises the value in a structured mentoring program for Indigenous students to navigate the journey from high school through to higher education. It emphasises the benefits of multi-modal approaches such as tutor squads, coaching and institutional course delivery. Importantly, the claims are linked to outcomes achieved as assessed through independent research and evaluation. Akin to Fricker's article, Irwin et al. reflect on a partnership approach developed between Southern Cross University, the University of New England, key agencies within the Clarence Valley region and the local community to plan and implement the Stellar program. This program emphasises the importance of working with Indigenous communities to achieve a local vision. The emphasis is on strong and trusting working relationships as the foundation to have on-going conversations about Indigenous higher education pathways.

Fredricks et al. reflect on a university based program entitled Community Aspirations Program in Education (CAP-ED) being implemented at Central Queensland University. This emphasises the need for program contextualisation built on strong, consistent and sustained community engagement. Thorn and Flodin describe key lessons learned during the planning and implementation of the Row AHEAD (Addressing Higher Educational Access Disadvantage) program at Curtin University, which uses sport as a vehicle to build higher education aspiration development and awareness raising among Indigenous high school students. Fleming and Grace discuss the ACT-Indigenous Success program that has been implemented through the University of Canberra. This also focuses on engaging high school students to explore higher education options and to develop respective goals.

Vitartas et al. report on a case study intervention known as Getting Down to Business, which aims to inspire young Indigenous students to pursue tertiary business studies. It uses successful Indigenous entrepreneurs and business people as exemplars to motivate students to think about business education as a potential higher education pathway. Importantly, this is linked to the Victorian Curriculum and Assessment Authority's business management study design, thus creating an explicit curriculum pathway between secondary and tertiary education.

Cairnduff 's paper moves towards a deeper appreciation of a systems approach to better support Indigenous students as they transition into higher education environments. She reports on the University of Sydney's Wingara Mura - Bunga Burrabugu Strategy which focuses on building 
cultural competence from the standpoint of Indigenous cultures through innovative learning, teaching, research and engagement. Hall and Wilkes build on this discussion by using student narratives to illustrate the importance of creating a culturally safe environment in the pre-tertiary entrance space. They draw on Indigenous student perspectives about their participation in an Indigenous-specific enabling program known as Preparation for Tertiary Success. This enabling program is implemented through the Australian Centre of Indigenous Knowledges and Education - a joint partnership between the Batchelor Institute of Indigenous Tertiary Education and Charles Darwin University. Their article highlights the centrality of cultural safety, whilst simultaneously recognising the inherent complexity of achieving this objective within a higher education environment.

This special issue provides a useful snapshot of an emerging evidence-base about Indigenous pathways and transitions into higher education in Australia. It draws on key learnings from current programs and will be a useful evidence source for the current House of Representatives Standing Committee on Indigenous Affairs inquiry into educational outcomes for Indigenous students. In particular, it highlights the necessity of a lifespan approach to education that recognises the linkages and supports between various stages of education spanning early childhood, primary and secondary schools, VET and tertiary education. To invest in one, without investing in the others, can be problematic for advancing lifelong education for Indigenous peoples in Australia.

One key challenge we face in Australia is to move beyond basic process and impact evaluation approaches about Indigenous higher education pathways and transitions. We need to develop more sophisticated evaluation models that reflect more rigorous, comprehensive and nuanced understandings of what Indigenous higher education trajectories look like, the inherent complexities they bring, how they can best be navigated, and the tangible outcomes Indigenousspecific programs can achieve. This includes the capacity to examine and monitor new and innovative institutional and organisational culture change to reform Indigenous education within higher education settings. This includes the adoption of whole-of-university approaches and the courage to navigate and implement complex system changes. Evaluations of this nature need to be funded appropriately and be a mandated element of government funded education programs. Emerging evaluation approaches that build on Indigenous knowledge systems could be useful in this regard. These will need to privilege Indigenous epistemologies, ontologies and axiologies. A commitment to a national meta-evaluation of HEPP, particularly Indigenous higher education investments, would also be a positive step forward for continuing to respond to recommendations within Bradley and Behrendt Reviews.

We see this special issue of the Learning Communities: International Journal of Learning in Social Contexts, in parallel to the delivery of the national forum entitled 'Engagement at the Interface: Indigenous Pathways and Transitions into High Education', as two key mechanisms to share and learn from the growing evidence-base about what does and does not work in relation to Indigenous pathways and transitions into higher education. This is only a start. Further debate and discussion is needed to move this important national agenda forward. We know that further investment into high quality research and evaluation focussing on the efficacy and effectiveness of Indigenous higher education programs and policies is required (Behrendt et al 2012). We argue that this includes a willingness to take risks with program and policy development; a preparedness to invest in innovative program delivery models; and a commitment to scale-up promising programs and policy responses that will advance Indigenous higher education outcomes in Australia. This special issue demonstrates that Indigenous higher education programs with a strong community vision, long-term funding security, and a sustainable outlook, are better equipped to support Indigenous higher education outcomes in Australia than those that do not. Let us learn from, and continue to build, the evidence-base that supports improved outcomes in Indigenous higher education in Australia. 


\section{References}

Behrendt, L., Larkin, S., Griew, R., \& Kelly, P. (2012). Review of higher education access and outcomes for Aboriginal and Torres Strait Islander people, final report. Retrieved from http://www.innovation.gov. au/highereducation/IndigenousHigherEducation/ReviewOfIndigenousHigherEducation/FinalReport/ IHERFinalReport.pdf

Bradley, D., Noonan, P., Nugent, H., \& Scales, B. (2008). Review of Australian Higher Education Final Report.

Retrieved from http://www.deewr.gov.au/HigherEducation/Review/Documents/PDF/Higher\%20 Education\%20Review_one\%20document_02.pdf

Gale, T. \& Parker. S. (2010). Student transition into higher education. ALTC Good Practice Report. Surry Hills, Australia: Australian Learning and Teaching Council

Naylor, R., Baik, C. \& James, R. (2013). Developing a Critical Interventions Framework for Advancing Equity in Australian Higher Education. Melbourne, Australia: Centre for the Study of Higher Education, The University of Melbourne.

Wilks, J. \& Wilson, K. (2015). Indigenous Australia: A profile of the Aboriginal and Torres Strait Islander higher education student population. Australian Universities' Review, 57(2), 17-30. 